\title{
Review of: "Population density and plant availability interplay to shape browsing intensity by roe deer in a deciduous forest"
}

Anna Wierzbicka

Potential competing interests: The author(s) declared that no potential competing interests exist.

It was such a pleasure to red about long time experiment about wild ruminants. We need more experiments like that and more articles about it.

Article is thorough and well written. I have only a few suggestions about improving Material and methods part (2.1. lines 91-95). As a forest ecologist I am lacking more detailed description of forest: please add soil type (general for the area) and forest type according to International Code of Phytosociological Nomenclature.

It is also lack of description of other animal species living on study area. Are there other deer species? Do wild boars are there? What about middle size predators? Please add one paragraph.

Other comments:

lines 138-141 - please add numbers to categories (it is 6 or 7?), it will be more clear.

I hope to see this work published soon 